DEMOGRAPHIC RESEARCH

VOLUME 39, ARTICLE 40, PAGES 1065-1080 PUBLISHED 14 NOVEMBER 2018

https://www.demographic-research.org/Volumes/Vol39/40/

DOI: 10.4054/DemRes.2018.39.40

Descriptive Finding

Child poverty across immigrant generations in the United States, 1993-2016: Evidence using the official and supplemental poverty measures

Brian C. Thiede

Matthew M. Brooks

(C) 2018 Brian C. Thiede \& Matthew M. Brooks.

This open-access work is published under the terms of the Creative Commons Attribution 3.0 Germany (CC BY 3.0 DE), which permits use, reproduction, and distribution in any medium, provided the original author(s) and source are given credit.

See https://creativecommons.org/licenses/by/3.0/de/legalcode. 


\section{Contents}

1 Introduction 1066

2 Data and methods 1067

3 Results 1068

4 Discussion 1075

$5 \quad$ Acknowledgements 1076

$\begin{array}{ll}\text { References } & 1077\end{array}$ 


\title{
Child poverty across immigrant generations in the United States, 1993-2016: Evidence using the official and supplemental poverty measures
}

\author{
Brian C. Thiede ${ }^{1}$ \\ Matthew M. Brooks ${ }^{2}$
}

\begin{abstract}

\section{BACKGROUND}

Recent increases in ethno-racial diversity in the United States are paralleled by growing representation of first- and second-generation immigrants, especially among children. Socioeconomic inequalities along the lines of immigrant generation, race, and ethnicity suggest such demographic changes may result in greater disparities among recent, more-diverse cohorts of children.
\end{abstract}

\section{OBJECTIVE}

Describe poverty rates among US children across five immigrant generation groups, using the US government's official poverty measure (OPM) and a supplemental poverty measure (SPM), which accounts for government transfers and costs of living.

\section{METHODS}

Using data from the Current Population Survey and historical SPM estimates from 1993-2016, we describe trends in child poverty, stratified by immigrant generation. We compare estimates of inter-generational differences and temporal changes based on the OPM and SPM, and we conduct stratified analyses for Hispanic and Asian children.

\section{RESULTS}

We find persistent differences in poverty rates between immigrant generations. Firstgeneration non-citizens and second-generation children with two foreign-born parents have consistently higher poverty rates than other generations, between which there are minimal disparities. Differences between OPM- and SPM-based estimates suggest public supports and costs of living have differential welfare effects across groups.

\section{CONTRIBUTION}

We provide a historical record of child poverty differentials across immigrant

\footnotetext{
${ }^{1}$ Pennsylvania State University, University Park, USA. Email: bct11@psu.edu.

${ }^{2}$ Pennsylvania State University, University Park, USA. Email: mfb5341@psu.edu.
} 
generations, which have been understudied. Results demonstrate heterogeneity in the economic status of first- and second-generation children, which would be masked using other immigrant-generation typologies. Differences in OPM- and SPM-based measures raise questions about inter-generational disparities in public supports and costs of living, and stratified results highlight the intersection of race, ethnicity, and nativity as axes of inequality.

\section{Introduction}

Racial and ethnic diversity across the US population has increased markedly over recent decades, and this trend is expected to continue into the future (Alba and Foner 2015; Frey 2014; Lee et al. 2017; Lichter and Qian 2018). Shifts in ethno-racial composition have been particularly dramatic among recent cohorts of children. In 2016, for example, members of non-white minority groups comprised $50.4 \%$ of children ages $0-5$ years, compared with $33.8 \%$ of adults ages $50-54$ years and $19.1 \%$ of adults aged 85 or older (US Census Bureau 2017). The high degree of ethno-racial diversity at the bottom of the age distribution is driven by recent patterns of immigration and fertility, including high levels of fertility among first- and second-generation immigrant adults (Frank and Heuveline 2005; Johnson and Lichter 2016; Jonsson and Rendall 2004). One understudied implication is that new cohorts of children are not only characterized by growing diversity racially and ethnically, but also in terms of immigrant generation.

These new patterns of diversity are unfolding within a US context that has historically been characterized by socioeconomic inequalities along the axes of race, ethnicity, and immigrant generation (Glick and Yabiku 2016; Hamilton et al. 2011; Iceland et al. 2014; Lichter 2013). However, relatively little is known about whether and how inter-generational disparities among adults translate into patterns of advantage and disadvantage among children (National Academy of Sciences 2016). Existing evidence is focused mainly on broad differences between native- and foreign-born children and is largely based on data collected prior to the recent uptick in ethno-racial diversity among US children (Lichter, Qian, and Crowley 2005; Van Hook, Brown, and Kwenda 2004). Likewise, there has been little attention to historical changes in such socioeconomic gradients among children as diversity has increased.

We draw attention to these issues by describing patterns of child poverty across immigrant generations between 1993 and 2016. We are addressing a straightforward but important empirical question. Previously documented patterns of inequality among immigrant and native-born adults will not necessarily map onto cohorts of children, whose economic circumstances are also a function of selective patterns of fertility, 
immigration, and settlement within the United States, as well as differential access to the safety net. We expect these and related processes to produce distinct intergenerational patterns of poverty among children. We also examine historical dynamics in child poverty, which is merited given the possibility that inter-generational inequalities have changed over time with growing ethno-racial diversity, shifts in the socioeconomic characteristics and geographic distribution of immigration populations, and changes to the policy environment (Heinrich 2018; Lichter, Sanders, and Johnson 2015; Mattingly and Pedroza 2018). Finally, accounting for these patterns is important given their longer-term implications, as childhood exposure to poverty has negative effects over the life course (Duncan, Ziol-Guest, and Kalil 2010; Hayward and Gorman 2004). As an important 2016 report on immigrant integration in the United States argued, economic conditions among immigrant children "provide a window to the future" (National Academy of Sciences 2016: 289).

\section{Data and methods}

We analyze data from the Annual Social and Economic Supplement (ASEC) of the Current Population Survey (CPS). The CPS has the advantage of collecting data on parental place of birth - and thus children's immigrant generation - regardless of whether the child and parent co-reside in a household. We use the Integrated Public Use Microdata Series (IPUMS) to extract data on immigrant generation and official poverty status among children ages 0 to 17 years for 1994 through $2017(\mathrm{~N}=1,254,895)$ (Flood et al. 2017). We begin in 1994 since it is the first year that detailed information on immigrant generation was collected in the CPS, and because the mid-1990s mark the beginning of a new era of increased immigration, dispersion to new immigrant destinations, and, we expect, changing economic patterns. Poverty status is defined for the prior calendar years (1993-2016), which we refer to when reporting findings.

We measure poverty using the US government's official poverty measure (OPM) and the alternative, supplemental poverty measure (SPM). The latter was produced in 2009 by the US Census Bureau and Bureau of Labor Statistics to address perceived shortcomings of the OPM (Iceland 2005). It accounts for the welfare effects of taxes, tax credits, and non-cash transfers; adjusts for variation in housing costs; and uses consumer expenditure-based poverty thresholds (Short 2012). Since the Census SPM is not available for the first 16 years in our dataset, we use historical SPM estimates produced by Fox and colleagues (2015). We do not fully describe their methodology for brevity, but underscore two details. First, the historical SPM estimates differ slightly from the Census SPM, such as by excluding geographic cost-of-living adjustments and relying on imputed data for some years. Second, the historical SPM time series switches 
to the Census SPM when it became available in the 2010 CPS. An implication is that historical SPM estimates may underestimate the welfare effects of new settlement patterns that emerged during the study period.

We stratify our child poverty estimates by immigrant generation, which is operationalized as a five-category typology. We distinguish between children who are (a) foreign-born and not US citizens; (b) foreign-born US citizens; (c) native-born to two foreign-born parents; (d) native-born to one foreign-born and one-native born parent; and (e) native-born to two native-born parents. Together, groups (a) and (b) comprise the first generation, groups (c) and (d) the second generation, and group (e) the third + generation. We measure parental nativity rather than citizenship since we cannot identify the latter among non-resident parents using the CPS. If citizenship is a stronger correlate of poverty than nativity, our approach may understate within-secondgeneration disparities relative to a parental citizenship-based classification.

Our descriptive analyses are as follows. We estimate child poverty rates stratified by immigrant generation and over the 1993-2016 period. We pool the data into twelve two-year periods to increase the precision of estimates and throughout our study apply the ASEC person-level weights (Flood et al. 2017). We estimate poverty rates using both the OPM and SPM, and we compare inter-generational and temporal patterns to identify differences in the aggregate poverty-reducing (increasing) effect of the factors captured in the SPM. Finally, we produce generation-specific estimates of child poverty among Hispanic and Asian children, respectively, to compare two large but socioeconomically distinct immigrant populations.

\section{Results}

To put our analyses of child poverty into context, we begin by describing changes in the distribution of children across immigrant generations (Figure 1). Growth in the share of children in the second immigrant generation has been most pronounced, increasing from $13.2 \%$ to $22.9 \%$ between $1993-1994$ and 2015-2016. More than two-thirds of second-generation children had two foreign-born parents in 2015-2016, and this group experienced the largest percentage-point increase in overall representation since 19931994 (7.6 points). The representation of second-generation children with only one foreign-born parent also increased over this period, from $5.2 \%$ to $7.3 \%$ of all children. First-generation immigrants comprised the smallest proportion of children throughout the study, and this share changed little over time (3.2\% to $3.6 \%$ ). Finally, we note that increasing representation of the first and second generations was offset by a 10.1 percentage-point decline in the share of children in the third + generation. This group nonetheless remains the large majority, representing over $70 \%$ of children in all periods. 
Figure 1: Distribution of children by immigrant generation, 1993-2016

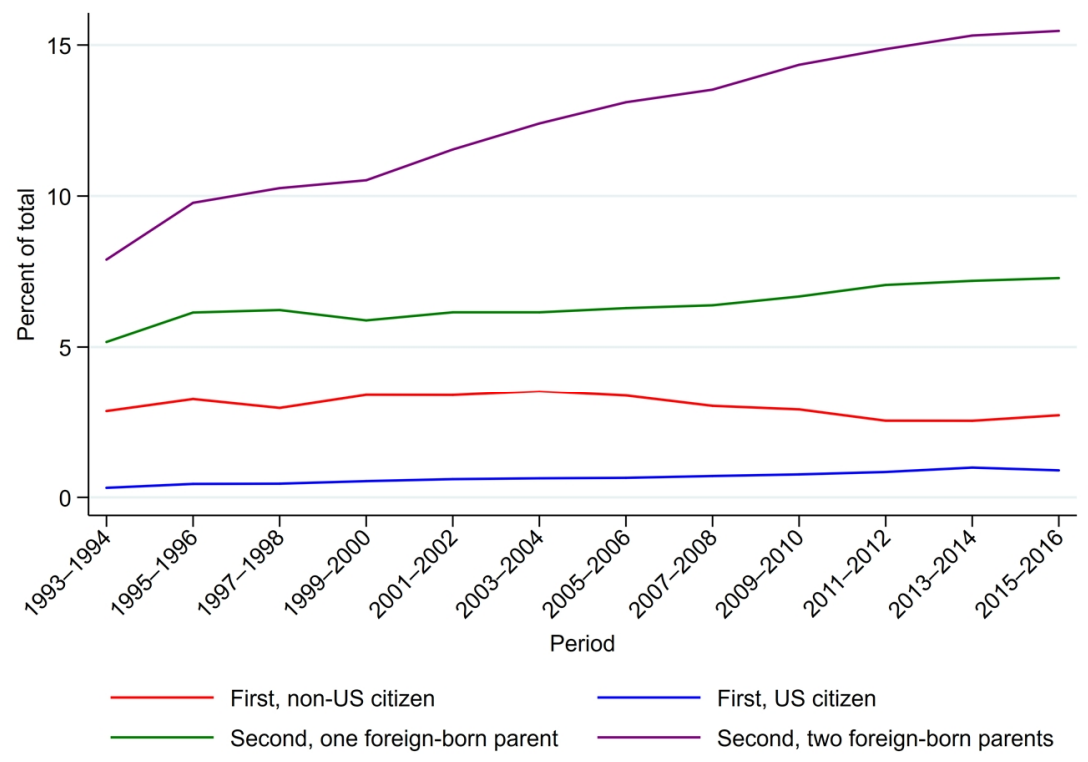

Note: Figure excludes the third+ generation.

Next, we examine patterns of poverty across immigrant generations, comparing OPM- and SPM-based estimates. Rates of poverty, as officially defined, are consistently highest among first-generation non-US citizen children, followed by second-generation children with two foreign-born parents (Figure 2a). Poverty rates for these two groups averaged $34.4 \%$ and $28.6 \%$, respectively, across the study period. The share of both groups of children in poverty fell from the start to the end of our study: from $46.7 \%$ to $30.2 \%$ among first-generation non-citizens and from $36.5 \%$ to $25.7 \%$ among second-generation children with two foreign-born parents. This decline was seemingly interrupted by the 'Great Recession' of 2007-2009 and its extended aftermath - evident, for example, in the uptick in poverty rates from $23.9 \%$ to $32.3 \%$ between 2005-2006 and 2011-2012 among second-generation children with two foreign-born parents. Also note that the gap in poverty rates between first-generation non-citizens and second-generation children with two foreign-born parents narrowed from 1993-1994 to 2015-2016 - from 10.2 to 4.5 percentage points - but is characterized by idiosyncratic fluctuations over time. 
Figure 2: Child poverty estimates by immigrant generation, 1993-2016 a) Official poverty measure

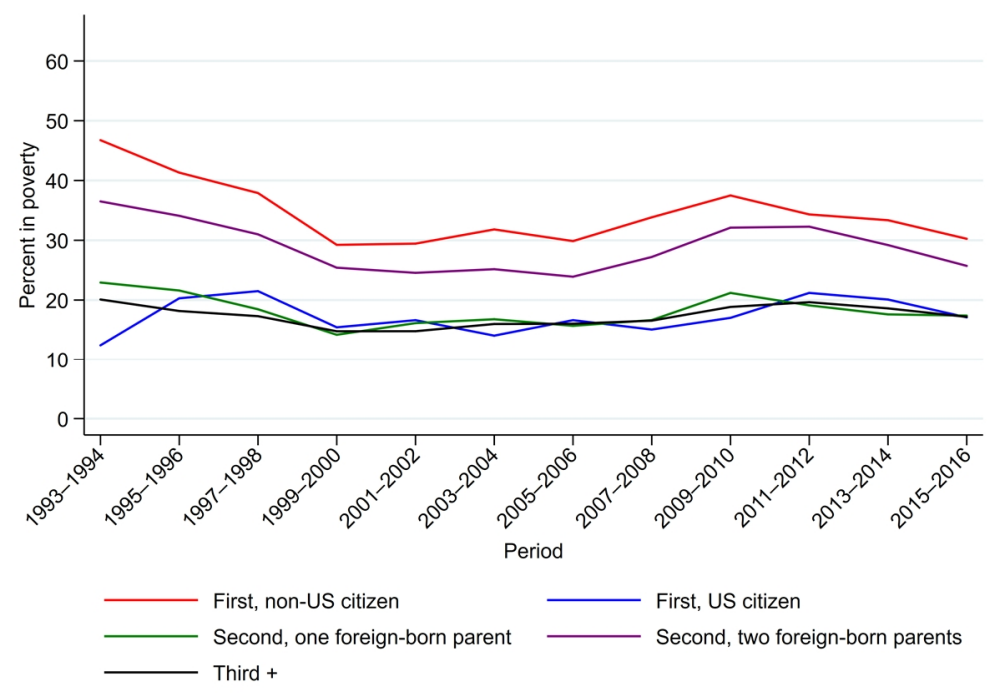

b) Supplemental poverty measure

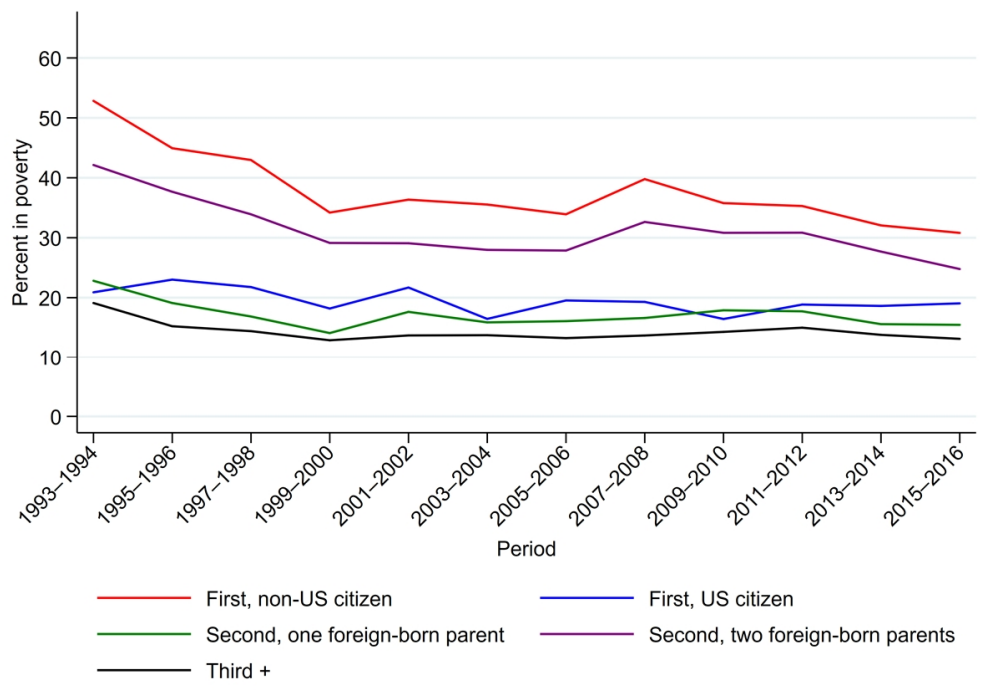


Official poverty rates among the other three immigrant generations were all markedly lower, though still high in absolute terms. Averaged across all periods, poverty rates among these three groups - first-generation US citizens, secondgeneration children with one foreign-born parent, and the third+ generation - fell within a range of $17.3 \%$ to $18.1 \%$. With few exceptions, child poverty rates among these three groups tracked closely together over time. Likewise, apart from an increase in poverty associated with the 2007-2009 recession, trendlines were relatively flat. For example, poverty among third+-generation children only declined from $20.1 \%$ to $17.2 \%$ from the start to the end of the study.

We then compare trends in child poverty across immigrant generations using the SPM (Figure 2b), which is particularly pertinent given disparities in employment, place of residence, and program eligibility and use across the populations of interest (De Jong et al. 2017; De Trinadad Young et al. 2018). Our comparison yields at least two important findings. First, the difference between OPM- and SPM-based estimates varies in magnitude and direction between immigrant generations. Poverty rates based on the OPM exceed SPM-based rates among the third+ generation $(17.3 \%$ vs. $14.4 \%)$ and second-generation children with one foreign-born parent $(18.1 \%$ vs. $17.0 \%)$, but they are lower among first-generation non-citizens (34.4\% vs. $37.8 \%)$ and citizens $(17.5 \%$ vs. $19.2 \%$ ) and among second-generation children with two foreign-born parents $(28.6 \%$ vs. $30.5 \%)$. The observed patterns raise important questions about intergenerational differences in safety net eligibility, program utilization, and costs of living.

Second, the OPM and SPM yield different trends over time. The decline in child poverty among first-generation non-citizens and second-generation children with two foreign-born parents during the first decade of our study is considerably steeper when poverty is measured using the SPM. For example, the SPM-based poverty rate among second-generation children with two foreign-born parents declined 17.4 points over the study period, compared with a 10.8 percentage-point decline in the OPM-based rate. This pattern may reflect the geographic dispersion of immigrant populations to new, lower-cost-of-living destinations. Our comparison also suggests that the safety net helped to mitigate the effects of the Great Recession, as the uptick in poverty between 2005-2006 and 2009-2010 is muted when measured using the SPM. The gap between OPM- and SPM-based estimates of recession-related increases in child poverty ranged from more than five percentage points among first-generation non-citizens (5.8 points) and second-generation children with two foreign-born parents (5.3 points) to 1.8 percentage points among the third + generation. 
Figure 3: Child poverty estimates by immigrant generation (Hispanic only), 1993-2016

a) Official poverty measure

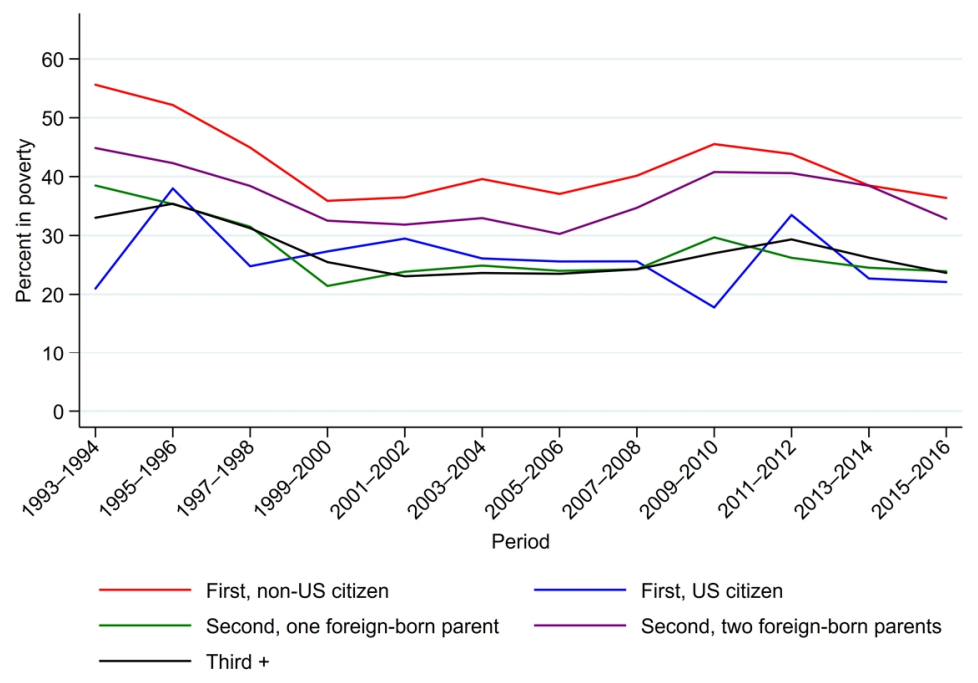

b) Supplemental poverty measure

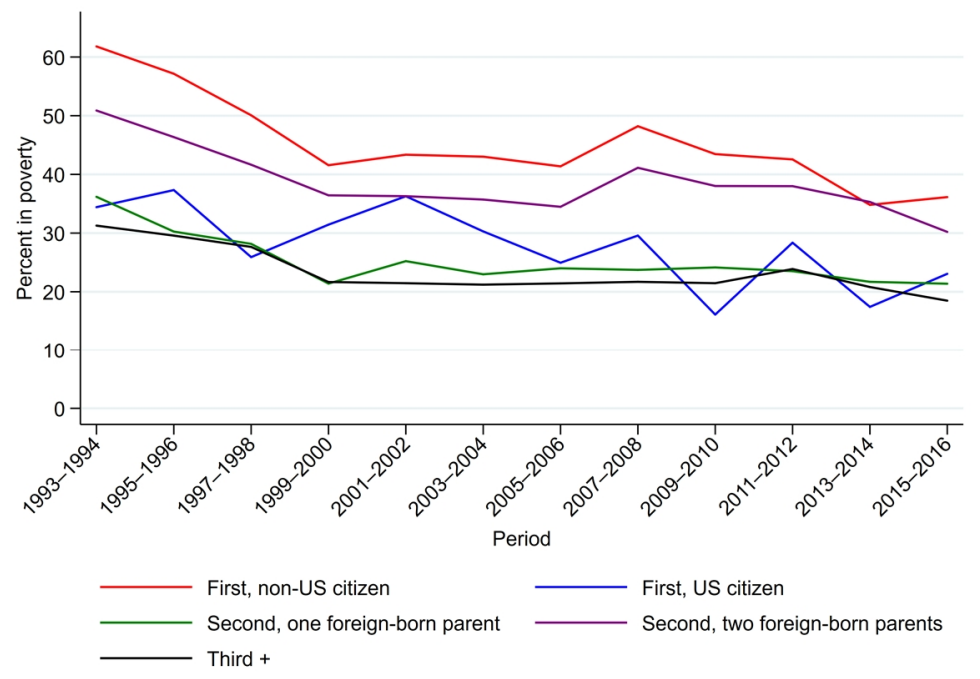


Since overall estimates of child poverty by immigrant generation may conceal variation in patterns across ethno-racial groups, we conduct a separate stratified analysis among the large but socioeconomically distinct Hispanic and Asian populations (Figures $3 \mathrm{a}-\mathrm{b}$ and $4 \mathrm{a}-\mathrm{b}$ ). Indeed, we find stark differences in absolute poverty levels among Hispanic and Asian children. Hispanic children face disproportionately high levels of poverty, regardless of generation, while Asian children face below-average poverty rates. For example, $26.6 \%$ of third+-generation Hispanic children were officially poor across our study period, compared with $17.3 \%$ nationally and $13.4 \%$ of Asian children. Notably, the inter-generational poverty gradient observed nationally is also apparent among Hispanic but not Asian children. Hispanic first-generation noncitizens and second-generation children with two foreign-born parents face much higher poverty rates than their Hispanic peers throughout the study. In contrast, only firstgeneration non-citizen Asian children are distinctively worse-off vis-à-vis their samerace peers.

Our results also reveal that the most disadvantaged Hispanic and Asian populations have experienced convergence in child poverty relative to other groups during the study period. SPM-based rates among Hispanic first-generation non-citizens and second-generation children with two foreign-born parents declined by 25.7 and 20.7 percentage points, respectively, compared with 22.0- and 17.4-point declines nationally. Supplemental poverty rates also declined disproportionately among the relatively disadvantaged group of first-generation non-citizen Asian children (19.7 points). Finally, among both Hispanic and Asian children, official poverty rates are greater than or nearly equal to SPM-based rates among the third+ generation and second-generation children with one foreign-born parent, but are distinctively lower among the other groups. These patterns suggest that inter-generational gradients in the aggregate welfare effects of safety net use and settlement patterns are fairly consistent across ethno-racial groups. 
Figure 4: Child poverty estimates by immigrant generation (Asian only), 1993-2016

a) Official poverty measure

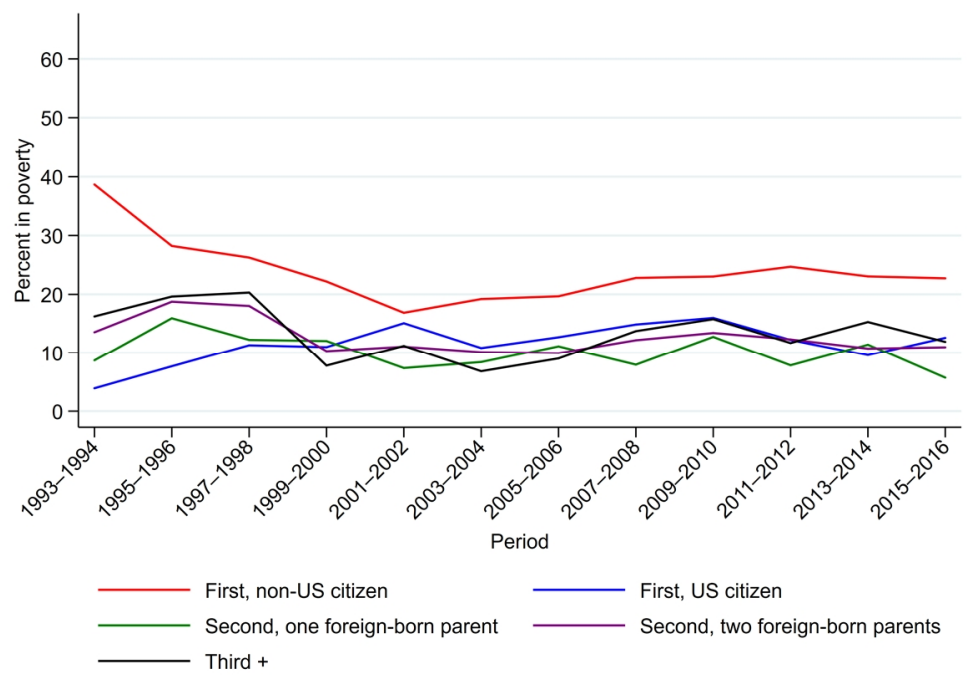

b) Supplemental poverty measure

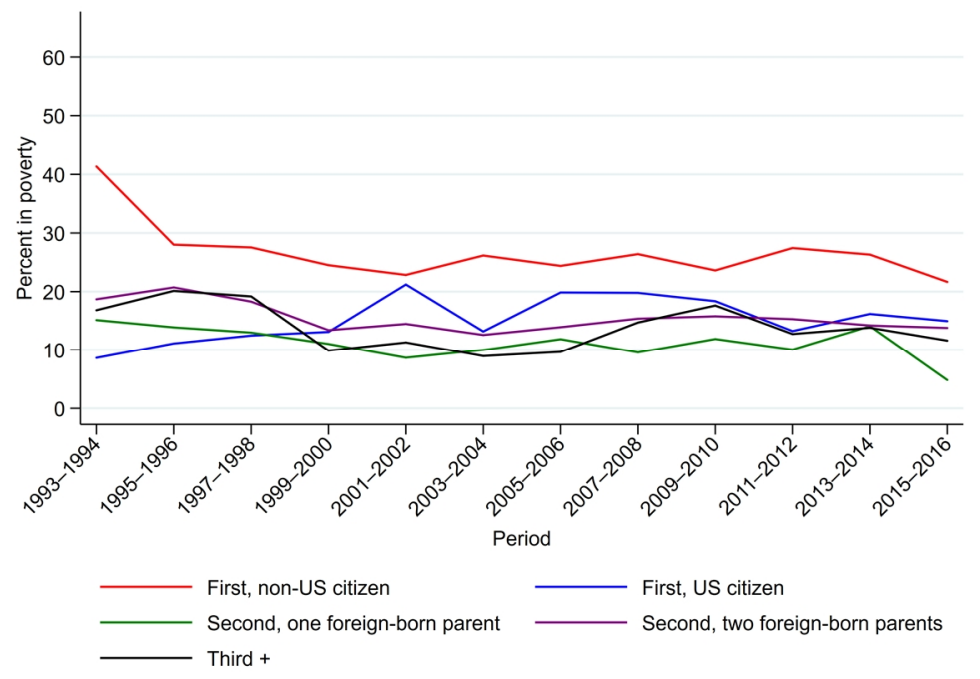




\section{Discussion}

Our analysis of child poverty across immigrant generations finds evidence of large differences according to child and parental nativity. First-generation US citizens and second-generation children with two foreign-born parents are at greater risk of poverty than the three other groups we consider, and this conclusion is supported using both the OPM and SPM. One implication of the inter-generational gradient that we document is that binary foreign- versus native-born comparisons, and those that compare aggregated first, second, and third + generations, will mask substantively important heterogeneity in child poverty levels within the first and second generations. Future research should therefore employ detailed typologies to the extent that data permit.

The inter-generational child poverty gaps described above were relatively persistent, but we nonetheless observed some convergence between the highest- and lowest-poverty generations. For example, in 1993-1994, the differences in OPM- and SPM-based estimates between first-generation non-citizens and the third + generation were 26.7 and 33.7 percentage points, respectively, but these gaps had decreased to 13.1 and 17.7 points in 2015-2016. While the OPM- and SPM-based estimates produce broadly similar conclusions with respect to the inter-generational gradient and temporal pattern in child poverty, the difference between these two measures varies across generations. The OPM yields higher estimates of poverty than the SPM among the third + generation and second-generation children with one foreign-born parent, but it yields lower estimates among the remaining three generations in our typology. We speculate that these patterns are driven largely by inter-generational differences in safety net eligibility and use, which is often tied to parental citizenship and proxied here by parental nativity. Future research should work to decompose the precise sources of these differences.

Our analysis of the Hispanic and Asian populations revealed stark differences in poverty between these groups, with disproportionately high poverty rates among the former and below-average rates among the latter. Inter-generational gradients in Hispanic child poverty were broadly similar to national trends, but among Asians only first-generation non-citizen children were distinctively worse-off than same-race peers. Within both groups, we observed patterns of convergence between the most- and leastdisadvantaged generations. Differences in OPM- and SPM-based poverty estimates also followed similar inter-generational patterns within both groups, which suggests that gradients in the aggregate welfare effects of the safety net and costs of living are consistent across ethno-racial groups.

We anticipate that the broad patterns we identified here will motivate additional research on economic disparities among children across immigrant generations, and into how such patterns interact with ethno-racial inequality during an era of growing 
diversity in the United States. In addition to the future research questions identified above, extensions of our work include comparing inter-generational gradients in child poverty across new and established destinations, studying the contribution of selective fertility and migration to child poverty patterns, and examining inter-generational differences in the frequency and duration of poverty spells.

\section{Acknowledgements}

The authors acknowledge the assistance provided by the Population Research Institute at Penn State University, which is supported by NIH infrastructure grant P2CHD04102. Thiede acknowledges the support of an extramural small grants program from the University of Wisconsin-Madison's Institute for Research on Poverty (IRP). 


\section{References}

Alba, R. and Foner, N. (2015). Strangers no more: Immigration and the challenges of integration in North America and Western Europe. Princeton: Princeton University Press. doi:10.1515/9781400865901.

De Jong, G.F., Graefe, D., Galvan, C., and Howe Hasanali, S. (2017). Unemployment and immigrant receptivity climate in established and newly emerging destination areas. Population Research and Policy Review 36(2): 157-180. doi:10.1007/ s11113-016-9408-y.

De Trinidad Young, M., Leon-Perez, G., Wells, C.R., and Wallace, S.P. (2018). More inclusive states, less poverty among immigrants? An examination of poverty, citizenship stratification, and state immigrant policies. Population Research and Policy Review 37(2): 205-228. doi:10.1007/s11113-018-9459-3.

Duncan, G.J., Ziol-Guest, K.M., and Kalil, A. (2010). Early-childhood poverty and adult attainment, behavior, and health. Child Development 81(1): 306-325. doi:10.1111/j.1467-8624.2009.01396.x.

Flood, S., King, M., Ruggles, S., and Warren, J.R. (2017). Integrated public use microdata series: Current population survey: Version 5.0. [dataset]. Minneapolis: University of Minnesota. https://www.ipums.org/doi/D030.V5.0.shtml.

Fox, L., Wimer, C., Garfinkel, I., Kaushal, N., and Waldfogel, J. (2015). Waging war on poverty: Poverty trends using a historical supplemental poverty measure. Journal of Policy Analysis and Management 34(3): 567-592. doi:10.1002/ pam.21833.

Frank, R. and Heuveline, P. (2005). A crossover in Mexican and Mexican-American fertility rates: Evidence and explanations for an emerging paradox. Demographic Research 12(4): 77-104. doi:10.4054/DemRes.2005.12.4.

Frey, W.H. (2014). Diversity explosion: How new racial demographics are remaking America. Washington, D.C.: Brookings Institution Press.

Glick, J.E. and Yabiku, S.T. (2016). Migrant children and migrants' children: Nativity differences in school enrollment in Mexico and the United States. Demographic Research 35(8): 201-228. doi:10.4054/DemRes.2016.35.8.

Hamilton, E.R., Cardoso, J.B., Hummer, R.A., and Padilla, Y.C. (2011). Assimilation and emerging health disparities among new generations of US children. Demographic Research 25(25): 783-818. doi:10.4054/DemRes.2011.25.25. 
Hayward, M.D. and Gorman, B.K. (2004). The long arm of childhood: The influence of early-life social conditions on men's mortality. Demography 41(1): 87-107. doi:10.1353/dem.2004.0005.

Heinrich, C.J. (2018). 'A thousand petty fortresses': Administrative burden in US immigration policies and its consequences. Journal of Policy Analysis and Management 37(2): 211-239. doi:10.1002/pam.22046.

Iceland, J. (2005). Measuring poverty: Theoretical and empirical considerations. Measurement: Interdisciplinary Research and Perspectives 3(4): 199-235. doi:10.1207/s15366359mea0304_1.

Iceland, J., Weinberg, D., and Hughes, L. (2014). The residential segregation of detailed Hispanic and Asian groups in the United States: 1980-2010. Demographic Research 31(20): 593-624. doi:10.4054/DemRes.2014.31.20.

Johnson, K.M. and Lichter, D.T. (2016). Diverging demography: Hispanic and nonHispanic contributions to US population redistribution and diversity. Population Research and Policy Review 35(5): 705-725. doi:10.1007/s11113-016-9403-3.

Jonsson, S.H. and Rendall, M.S. (2004). The fertility contribution of Mexican immigration to the United States. Demography 41(1): 129-150. doi:10.1353/ dem.2004.0006.

Lee, B.A., Martin, M.J., Matthews, S.A., and Farrell, C.R. (2017). State-level changes in US racial and ethnic diversity, 1980 to 2015: A universal trend? Demographic Research 37(33): 1031-1048. doi:10.4054/DemRes.2017.37.33.

Lichter, D.T. (2013). Integration or fragmentation? Racial diversity and the American future. Demography 50(2): 359-391. doi:10.1007/s13524-013-0197-1.

Lichter, D.T. and Qian, Z. (2018). Children at risk: Diversity, inequality, and the third demographic transition. In: Poston, D.L. (ed.). Low fertility regimes and demographic and societal change. Basel: Springer: 169-191. doi:10.1007/9783-319-64061-7_10.

Lichter, D.T., Qian, Z., and Crowley, M.L. (2005). Child poverty among racial minorities and immigrants: Explaining trends and differentials. Social Science Quarterly 86(S1): 1037-1059. doi:10.1111/j.0038-4941.2005.00335.x.

Lichter, D.T., Sanders, S.R., and Johnson, K.M. (2015). Hispanics at the starting line: Poverty among newborn infants in established gateways and new destinations. Social Forces 94(1): 209-235. doi:10.1093/sf/sov043. 
Mattingly, M.J. and Pedroza, J.M. (2018). Convergence and disadvantage in poverty trends (1980-2010): What is driving the relative socioeconomic position of Hispanics and Whites? Race and Social Problems 10(1): 53-66. doi:10.1007/ s12552-017-9221-1.

National Academies of Sciences (2016). The integration of immigrants into American society. Washington, D.C.: National Academies Press.

Short, K. (2012). The research supplemental poverty measure: 2011. Suitland: US Census Bureau.

US Census Bureau (2017). Annual estimates of the resident population by sex, age, race, and Hispanic origin for the United States and states: April 1, 2010 to July 1, 2016 [electronic resource]. Suitland: US Census Bureau, Population Division. https://factfinder.census.gov/faces/tableservices/jsf/pages/productview.xhtml?src $=$ bkmk.

Van Hook, J., Brown, S.I., and Kwenda, M.N. (2004). A decomposition of trends in poverty among children of immigrants. Demography 41(4): 649-670. doi:10.1353/dem.2004.0038. 
Thiede \& Brooks: Child poverty across immigrant generations in the United States, 1993-2016 